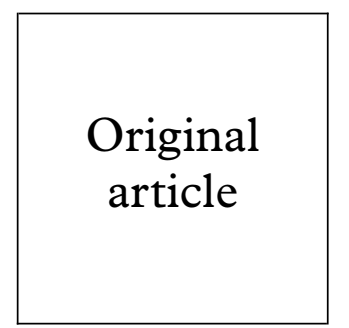

\title{
Analysis of quinolone resistance mechanisms in Neisseria gonorrhoeae isolates in vitro
}

\author{
Masatoshi Tanaka, Shunzi Sakuma, Koichi Takahashi, Tatsuo Nagahuzi, Takeshi Saika, \\ Intetsu Kobayashi, Joichi Kumazawa
}

Background and objectives: Gonococcal fluoroquinolone resistance is now a significant problem in Japan. We generated gonococcal mutants resistant to norfloxacin in vitro from norfloxacin sensitive isolates and analysed the contribution of three known mechanisms of quinolone resistance in Neisseria gonorrhoeae.

Materials and methods: Three clinical isolates of $N$ gonorrhoeae susceptible to norfloxacin were exposed to increasing concentrations of norfloxacin. To identify mutations in the $\operatorname{gyr} A$ and $\operatorname{par} C$ genes of the gonococcal mutants, the quinolone resistance determining regions of the gyr $A$ and parC genes were polymerase chain reaction (PCR) amplified and the PCR products were directly sequenced. Norfloxacin accumulation in the gonococcal cells was also measured.

Results: The MICs of norfloxacin for three variants containing a single GyrA mutation were 16-fold higher than that for their parent isolates. A variant showing reduced norfloxacin accumulation in the cells, without mutations in the GyrA or ParC proteins, was also less sensitive to norfloxacin, with a 16-fold increase in the MIC, compared with the parent strain. The MIC of norfloxacin for a variant which contained a single GyrA mutation with reduced norfloxacin accumulation in the cells was 128 -fold higher than for the parent strain. A variant containing mutations in both GyrA and ParC proteins with reduced accumulation of norfloxacin in the cells showed a 256-fold increase in the norfloxacin MIC compared with the parent strain. There was no variant containing a ParC mutation without the simultaneous presence of a GyrA mutation.

Conclusions: The results from this study suggest that not only a mutation in the gyrA gene but also reduced drug accumulation in cells contributes to the development of fluoroquinolone resistance in gonococci and that a mutation in the $\operatorname{par} C$ gene with the simultaneous presence of a mutation in the gyr $A$ gene contributes to a high level of fluoroquinolone resistance in gonococci with decreases in accumulation in cells having an additional but lesser effect. (Sex Transm Inf 1998;74:59-62)

Keywords: quinolone resistance; Neisseria gonorrhoeae; mutation; gyrA gene; parC gene; norfloxacin accumulation

\section{Introduction}

Fluoroquinolones are very effective as oral single dose treatment for infections caused by Neisseria gonorrhoeae. Fluoroquinolone regimens have been increasingly used in various countries including Japan. Recently, gonococcal isolates with reduced susceptibility to fluoroquinolones have been identified in several countries. ${ }^{1-7}$ In Japan, gonococcal fluoroquinolone resistance is now a significant problem. $^{89}$

In $N$ gonorrhoeae, three mechanisms of fluoroquinolone resistance have been reported: (i) the development of mutations in the DNA gyrase subunit A (GyrA) encoded by the gyrA gene, ${ }^{10}{ }^{11}$ (ii) mutations in the DNA topoisomerase IV encoded by the parC gene, ${ }^{10}$ and (iii) reduced quinolone accumulation in the cells. ${ }^{12}$ Mutations at serine-91 and at aspartic acid-95 in the gonococcal GyrA protein are the commonly identified mutations in quinolone resistant isolates. ${ }^{10}{ }^{11}$ However, no single mutation in the parC gene, without the coexistence of a mutation in the gyr $A$ gene, has been detected. ${ }^{10}$ These findings suggest that in the development of gonococcal fluoroquinolone resistance a mutation within the gyrA gene may be more important than that within the parC gene. Reduced accumulation of quinolone within bacterial cells is also known to play a role in the quinolone resistance in several bacterial species. ${ }^{13-17}$ However, its mechanism remains unclear in several points in $N$ gonorrhoeae. ${ }^{12}$

We are interested in determining how a $N$ gonorrhoeae isolate acquires quinolone resistance in vitro. We generated gonococcal variants resistant to norfloxacin by exposing three clinical isolates susceptible to norfloxacin to increasing concentrations of norfloxacin in vitro. We analysed the contributions of the three known mechanisms of quinolone resistance.

\section{Materials and methods}

BACTERIAL STRAINS

$N$ gonorrhoeae wild type (WT) strains used in this study were A67/WT, A69/WT, and A219/ WT. The three strains were isolated from Japanese men with acute urethritis. $N$ gonorrhoeae was identified as Gram negative diplococcus on Gram stain and by the oxidase reaction and the sugar utilisation pattern.

SELECTION OF THE N GONORRHOEAE RESISTANT TO NORFLOXACIN

Each wild type strain was cultured overnight on a GC plate (Becton Dickinson, USA). Approximately $10^{10}$ colony forming units (cfu) of 
each strain were then plated on GC agar containing norfloxacin $(1 \times$ minimum inhibitory concentration (MIC)). These plates were incubated at $35^{\circ} \mathrm{C}$ for 48 hours in a $5 \%$ carbon dioxide atmosphere. Growing bacteria were replated on GC agar containing the same concentration of norfloxacin for one additional 48 hour cycle. In the following selection step, bacteria were cultured on GC agar containing a doubled concentration $(2 \times$ original MIC) of norfloxacin. A resistant isolate was grown up and replated as before on GC plates containing the same concentration of norfloxacin. This protocol was repeated for additional cycles. At each step, single colonies were collected for susceptibility testing, DNA sequencing, and an assay of norfloxacin accumulation in the cells.

\section{ANTIBIOTIC SUSCEPTIBILITY TESTING}

The MIC for the wild type and norfloxacin selected variants was determined using an agar dilution technique with a GC agar base containing 1\% Iso VitaleX (Becton Dickinson) and twofold dilutions of the antibiotic. Plates were inoculated with $5 \mu \mathrm{l}$ of $10^{6} \mathrm{cfu} / \mathrm{ml}$ of each isolate using a multipoint inoculator. The plates were incubated at $35^{\circ} \mathrm{C}$ for 24 hours in a $5 \%$ carbon dioxide atmosphere. MICs were defined as the lowest antibiotic concentration that inhibited bacterial growth. The antibiotics which were tested were three fluoroquinolones: norfloxacin, ciprofloxacin, and DU6859a, as well as ampicillin, ceftriaxone, cefoteram, imipenem, azithromycin, and spectinomycin. All of the antibiotics were obtained in powder form from their manufactures. $\beta$ lactamase production was tested by an acidometric assay ( $\beta$ check; Pfizer Pharmaceuticals Inc, Japan).

\section{EXTRACTION OF DNA AND ANALYSIS}

Polymerase chain reaction (PCR) and direct DNA sequencing were performed to identify mutations in the $\operatorname{gyr} A$ and $\operatorname{par} C$ genes in the norfloxacin selected variants. Chromosomal DNA was extracted using standard methods ${ }^{18}$ and was subjected to PCR. The oligonucleotide primers which were used in the PCR amplification of the $\operatorname{gyr} A$ gene have been described previously. ${ }^{11}$ For amplification of the parC gene, two primers (the forward primer: 5'-ATGCGCGATATGGGTTTGAC-3' and the reverse primer: 5'-AACGCCTTAACG ACAACAGG-3') were produced by a DNA synthesiser, according to the sequences which have been reported previously. ${ }^{10}$ The parC gene sequence was determined from nucleotides 166 to 420 which correspond to the amino acids from 56 to 140 of the gonococcal ParC protein. This includes the quinolone resistance determining region (QRDR) (amino acids 66 to 119 of the gonococcal ParC protein)..$^{10}$

PCR amplification was performed in $25 \mu \mathrm{l}$ of a reaction mixture which contained $2.5 \mu \mathrm{l}$ of $10 \mathrm{x}$ Taq polymerase buffer $(500 \mathrm{mM} \mathrm{KCl}, 100$ $\mathrm{mM}$ TRIS-HCl ( $\mathrm{pH} 8.3$ ), $15 \mathrm{mM} \mathrm{MgCl}_{2}$, $0.1 \%$ gelatin), $0.25 \mu \mathrm{l}$ of each of the two primers $(25 \mathrm{pmol} / \mu \mathrm{l}), 0.5 \mu \mathrm{l}$ of each of the four deoxynucleotide triphosphates $(10 \mathrm{mM}), 0.2 \mu \mathrm{l}$

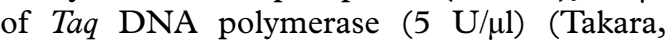
Japan), $2.5 \mu \mathrm{l}$ of TritonX-100 (2 mg/ml), and
$1.0 \mu \mathrm{l}$ of template DNA $(100 \mathrm{ng} / \mu \mathrm{l})$. Thirty five cycles were performed for each reaction. Each cycle consisted of 30 seconds at $93^{\circ} \mathrm{C}, 1$ minute at $52^{\circ} \mathrm{C}$, and 1 minute at $72^{\circ} \mathrm{C}$.

PCR amplification products were directly sequenced by the dideoxy chain termination method, ${ }^{19}$ using the Taq DyeDeoxy Terminator Cycle Sequencing Kit and Model 373A autosequencer (ABI, USA).

\section{NORFLOXACIN ACCUMULATION}

The accumulation of norfloxacin within gonococcal cells was measured using a modification of a method previously described. ${ }^{12}$ Briefly, gonococcal strains were grown on GC agar at $35^{\circ} \mathrm{C}$ for 24 hours in a $5 \%$ carbon dioxide atmosphere. A bacterial cell suspension was prepared in prewarmed GC medium to an optical density of 7.0 at $570 \mathrm{~nm}$. Norfloxacin was added to the bacterial suspension to a final concentration of $10 \mu \mathrm{g} / \mathrm{ml}$. The suspension was incubated at $37^{\circ} \mathrm{C}$ while being agitated. After incubation for 20 minutes, $10 \mathrm{ml}$ samples were taken. These samples were chilled. Cells were collected after sedimentation by centrifugation and then washed in $2 \mathrm{ml}$ of saline. The cells were then resuspended in 1 $\mathrm{ml}$ of saline. This suspension was immersed in boiling water for 7 minutes and then centrifuged. The concentration of norfloxacin in the supernatant was measured by a bioassay using Escherichia coli NIHJ JC-2. The amount of norfloxacin initially absorbed by the cells after its addition to the bacterial suspension was recorded. The accumulation of norfloxacin was calculated by subtracting the absorbed norfloxacin at time zero from the total norfloxacin eluted.

ANALYSIS OF OUTER MEMBRANE PROTEINS

The outer membrane proteins (OMPs) were prepared using the methods described by Sawai et $a l^{20}$ and separated on a sodium dodecyl sulphate $12 \%$ polyacrylamide gel.

\section{Results}

SELECTION OF NORFLOXACIN RESISTANT N GONORRHOEAE

Norfloxacin resistant variants were generated by exposing three wild type $N$ gonorrhoeae strains (A67/WT, A69/WT, and A219/WT) to increasing concentrations of norfloxacin. A67/A, A69/A, and A219/A were variants from each parental isolate after eight cycles. A67/B, A69/B, and A219/B were variants from each parental isolate after being cycled 18,14 , and 10 times, respectively.

A significant reduction in the sensitivity to norfloxacin was observed in the six norfloxacin selected variants (table 1). The MICs of norfloxacin for isolates A67/A and A67/B were 16 and 256-fold higher than that for the parental isolate A67/WT. Variants A69/A and A69/B were also less sensitive to norfloxacin, with a 16 and 128-fold increase in the MICs, respectively, compared with the parent strain A69/ WT. The MICs of norfloxacin for both A219/A and $219 / \mathrm{B}$ strains were 16-fold higher than for the parent strain A219/WT. The six norfloxacin resistant variants demonstrated cross resist- 
Table 1 Susceptibilities of wild type and variant Neisseria gonorrhoeae to various antibiotics

\begin{tabular}{|c|c|c|c|c|c|c|c|c|c|}
\hline \multirow[b]{2}{*}{ Strain } & \multicolumn{9}{|l|}{$M I C(\mu g / m l)$} \\
\hline & $N F L X^{\star}$ & $C P F X$ & $D U 6859 a$ & $A B P C$ & CTRX & CFTM & $I P M$ & $A Z M$ & $S P C M$ \\
\hline A67/WT & $0.016(1 \times) \dagger$ & $0.004(1 \times)$ & $0.002(1 \times)$ & 0.25 & 0.031 & 0.063 & 0.063 & 0.016 & 4.0 \\
\hline A67/A & $0.25(16 \times)$ & $0.063(16 \times)$ & $0.004(2 \times)$ & 0.25 & 0.031 & 0.125 & 0.125 & 0.016 & 4.0 \\
\hline A67/B & $4.0(256 \times)$ & $0.5(128 \times)$ & $0.031(16 \times)$ & 0.25 & 0.008 & 0.031 & 0.031 & 0.063 & 2.0 \\
\hline A69/WT & $0.004(1 \times)$ & $0.004(1 \times)$ & $0.002(1 \times)$ & 0.125 & 0.004 & 0.016 & 0.063 & 0.031 & 4.0 \\
\hline A69/A & $0.063(16 x)$ & $0.016(4 \times)$ & $0.002(1 \times)$ & 0.25 & 0.002 & 0.031 & 0.125 & 0.016 & 4.0 \\
\hline A69/B & $0.5(128 x)$ & $0.063(16 \times)$ & $0.008(4 \times)$ & 0.125 & 0.004 & 0.016 & 0.063 & 0.031 & 8.0 \\
\hline A219/WT & $0.031(1 \times)$ & $0.008(1 \times)$ & $0.002(1 \times)$ & 0.25 & 0.004 & 0.016 & 0.125 & 0.031 & 8.0 \\
\hline A219/A & $0.5(16 \times)$ & $0.125(16 \times)$ & $0.008(4 \times)$ & 0.25 & 0.004 & 0.016 & 0.063 & 0.031 & 8.0 \\
\hline A219/B & $0.5(16 x)$ & $0.125(16 \times)$ & $0.008(4 \times)$ & 0.125 & 0.004 & 0.016 & 0.063 & 0.016 & 4.0 \\
\hline
\end{tabular}

$\star$ NFLX = norfloxacin CPFX = ciprofloxacin ABPC = ampicillin CTRX = ceftriaxone CFTM $=$ cefoteram; IPM $=$ imipenem $\mathrm{AZM}=$ azithromycin; $\mathrm{SPCM}=$ spectinomycin; $\mathrm{WT}=$ wild type .

† The numbers in parentheses indicate the fold changes in MIC for a variant and its parent.

ance to two other fluoroquinolones: ciprofloxacin and DU6859a. No significant differences in the MICs of ampicillin, ceftriaxone, cefoteram, imipenem, azithromycin, or spectinomycin were found between the six norfloxacin selected variants and their parental isolates. These results indicate that the norfloxacin selected variants were resistant only to fluoroquinolones.

\section{IDENTIFICATION OF gyra AND parC GENE}

MUTATIONS

Mutations in the gyrA and parC genes are shown in table 2 The sequence analysis of the gyr $A$ gene revealed no substitutions in the three wild type strains or the variant A69/A. An aspartic acid (GAC) to tyrosine (TAC) substitution at codon 95 in the variants A67/A and $\mathrm{A} 67 / \mathrm{B}$, and an aspartic acid (GAC) to asparagine (AAC) substitution at codon 95 in the variant A69/B were detected. A substitution of a serine (TCC) to tyrosine (TAC) at codon 91 was also found in the variants A219/A and A219/B.

Sequence analysis of the $\operatorname{par} C$ gene demonstrated a glutamic acid (GAG) to valine (GTG) substitution at codon 91 only in the A67/B strain. No mutations in the parC gene were identified in the wild type isolates or the other variants.

NORFLOXACIN ACCUMULATION

Figure 1 illustrates the norfloxacin accumulation data. These experiments were performed at least in triplicate. A dramatic reduction in the accumulation level of norfloxacin was seen in the variants A69/A and A69/B in comparison with that in the parental A69/WT. The variants A67/A and A67/B also showed de-

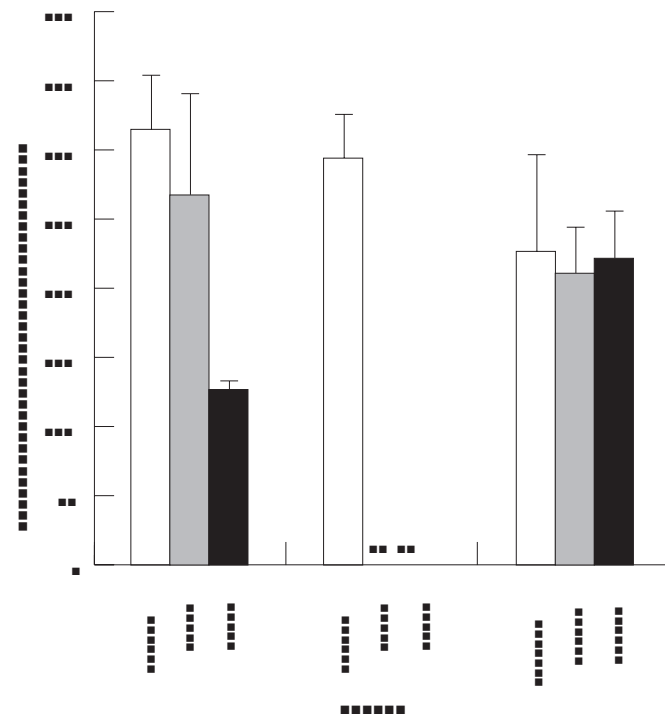

Figure 1 Norfloxacin (NFLX) accumulation (mean (SD)) in 20 minutes by gonococcal cells. These experiments were performed at least in triplicate. $b d=b e l o w$ detection.

creased norfloxacin accumulation compared with the parent isolate A67/WT, although the reduction in the accumulation level in the variant A67/A was slight. However, no significant differences in the accumulation levels between A219/WT and its variants A219/A and A219/B were found.

ANALYSIS OF OUTER MEMBRANE PROTEINS

The OMP profiles of all of the norfloxacin resistant strains and their parental isolates were analysed. However, no differences were identified between the norfloxacin selected variants and their parental isolates (data not shown).

Table 2 Mutations in the quinolone resistance determining region of the gyrA and parC genes in N gonorrhoeae. Nucleotides 265 to 291 of the gyrA gene coding for amino acids 89 to 97, and nucleotides 256 to 282 of the parC gene coding for amino acids 86 to 94 are shown. Dashes indicate sequence homology

\begin{tabular}{|c|c|c|c|c|c|c|c|c|c|c|c|c|c|c|c|c|c|c|}
\hline \multirow[b]{2}{*}{ Strain } & \multicolumn{9}{|c|}{ gyrA mutation } & \multicolumn{9}{|c|}{ parC mutation } \\
\hline & $\begin{array}{l}89 \\
\text { Gly }\end{array}$ & $A s p$ & $\begin{array}{l}91 \\
\text { Ser }\end{array}$ & Ala & Val & Tyr & $\begin{array}{l}95 \\
A s p\end{array}$ & $T h r$ & $\begin{array}{l}97 \\
\text { Ile }\end{array}$ & $\begin{array}{l}86 \\
A s p\end{array}$ & Ser & Ser & Ala & Tyr & $\begin{array}{l}91 \\
\text { Glu }\end{array}$ & Ala & Met & $\begin{array}{l}94 \\
\text { Val }\end{array}$ \\
\hline Wild type & GGC & GAT & TCC & GCA & GTT & TAC & GAC & ACC & ATC & GAC & AGT & TCC & GCC & TAT & GAG & GCG & ATG & GTG \\
\hline $\mathrm{A} 67 / \mathrm{A}$ & --- & --- & --- & --- & --- & --- & $\begin{array}{l}\text { T-- } \\
\text { Tyr }\end{array}$ & --- & --- & --- & --- & --- & --- & --- & --- & --- & --- & -- \\
\hline A67/B & -- & -- & -- & -- & -- & -- & $\begin{array}{l}\text { T-- } \\
\text { Tyr }\end{array}$ & -- & -- & -- & --- & -- & -- & --- & $\begin{array}{l}\text {-T- } \\
\text { Val }\end{array}$ & -- & -- & -- \\
\hline A69/A & --- & --- & --- & --- & --- & --- & -- & --- & -- & --- & --- & --- & --- & --- & --- & --- & --- & --- \\
\hline A69/B & -- & -- & -- & -- & -- & -- & $\begin{array}{l}\text { A-- } \\
\text { Asn }\end{array}$ & -- & -- & -- & -- & -- & -- & -- & -- & -- & -- & -- \\
\hline A219/A, B & --- & --- & $\begin{array}{l}\text {-A- } \\
\text { Tyr }\end{array}$ & --- & --- & --- & --- & --- & --- & --- & --- & --- & --- & --- & --- & --- & -- & -- \\
\hline
\end{tabular}




\section{Discussion}

Belland et $a l^{10}$ have recently generated a series of ciprofloxacin resistant mutants by exposing a $N$ gonorrhoeae isolate to increasing concentrations of ciprofloxacin. They have identified mutations in the gyr $A$ and parC genes in these ciprofloxacin resistant strains. However, no mutation in the parC gene, without the simultaneous presence of a mutation in the gyr $A$ gene has been identified. Their results have demonstrated that the serine-91 to phenylalanine substitution in the GyrA protein may be an important mutation in the development of gonococcal ciprofloxacin resistance. However, they have not examined whether the ciprofloxacin resistant variants displayed reduced accumulation of the drug in the cells.

In this investigation, we were able to generate several norfloxacin resistant mutants. All three wild type strains finally developed a mutation in the GyrA protein, although the mutation patterns differed. The MICs of norfloxacin for the variants A67/A, A219/A, and A219/B containing a single GyrA mutation were 16-fold higher than that for their parental isolates. The A69/A variant showing a markedly reduced norfloxacin accumulation in the cells, without mutations in the GyrA or ParC proteins, was also less sensitive to norfloxacin, with a 16 -fold increase in the MIC, compared with the parent strain. The MIC of norfloxacin for the A69/B variant which contained a single GyrA mutation with reduced norfloxacin accumulation in the cells was 128-fold higher than for the parent strain. The MICs of norfloxacin for these five variants ranged from 0.063 to 0.5 $\mu \mathrm{g} / \mathrm{ml}$. These findings indicate that for the development of gonococcal fluoroquinolone resistance a mutation in the gyrA gene should be present and that a mutation leading to reduced drug accumulation also contributes to the development of fluoroquinolone resistance. Of the three parental isolates, only the A67/WT strain developed all the three known fluoroquinolone resistance mechanisms. The A67/A variant contained the Asp-95 $\rightarrow$ Tyr substitution in the GyrA protein and demonstrated 16-fold reduction in the MIC of norfloxacin compared with A67/WT. The A67/B variant acquired a Glu-91 $\rightarrow$ Val mutation in the ParC protein in addition to the pre-existing Asp$95 \rightarrow$ Tyr mutation in GyrA, and was remarkably resistant to norfloxacin as evidence by a norfloxacin MIC of $4.0 \mu \mathrm{g} / \mathrm{ml}$ which was 256 times that of the A67/WT strain. In addition, this isolate showed significantly decreased accumulation of norfloxacin. These data suggest that a mutation in the $\operatorname{par} C$ gene with the simultaneous presence of a mutation in the gyr $A$ gene contributes a high level of fluoroquinolone resistance in gonococci with decreases in accumulation in cells having an additional but lesser effect.

In Gram negative bacteria such as $E$ coli, fluoroquinolone resistant mutants with a reduction or loss of OMP F (porin) have been isolated. ${ }^{21}{ }^{22}$ In the present study, to determine whether alterations occurred in the structural elements of the outer membrane of the fluoroquinolone resistant $N$ gonorrhoeae variants, we compared the OMP profiles of the variants with their parents. However, no differences were identified in OMP profiles between the fluoroquinolone resistant variants with or without decreased norfloxacin accumulation and the parental isolates. Therefore, it is suggested that the gonococcal variants have other mechanism such as active efflux system across the inner membrane ${ }^{17}$ leading to reduced norfloxacin accumulation in the cells.

1 Gransden WR, Warren CA, Phillips I, Hodges M, Barlow D. Decreased susceptibility of Neisseria gonorrhoeae to ciprofloxacin. Lancet 1990;335:51.

2 Jephcott AE, Turner A. Ciprofloxacin resistance in gonococci. Lancet 1990;335:165.

3 Clendennen III TE, Hames CS, Kees ES, et al. In vitro antibiotic susceptibilities of Neisseria gonorrhoeae isolates in the Philippines. Antimicrob Agents Chemother 1992;36:27782

4 Bogaerts J, Tello WM, Akingeneye J, et al. Effectiveness of norfloxacin and ofloxacin for treatment of gonorrhoea and decrease of in vitro susceptibility to quinolones over time in Rwanda. Genitourin Med 1993;69:196-200.

5 Knapp JS, Washington JA, Doyle LJ, et al. Persistence of Neisseria gonorrhoeae strains with decreased susceptibilities to ciprofloxacin and ofloxacin in Cleveland, Ohio, from 1992 through 1993. Antimicrob Agents Chemother 1994;38: 1992 throug

6 Knapp JS, Ohye R, Neal SW, et al. Emerging in vitro resistance to quinolones in penicillinase-producing Neisseria gonorrhoeae strains in Hawaii. Antimicrob Agents Chemother 1994;38:2200-3.

7 Kam KM, Lo KK, Ho NgK, Cheung MM. Rapid decline in penicillinase producing Neisseria gonorrhoeae in Hong Kong associated with emerging 4-fluoroquinolone resistance. Genitourin Med 1995;71:141-4.

8 Tanaka M, Kumazawa J, Matsumoto T, Kobayashi I. High prevalence of Neisseria gonorrhoeae strains with reduced susceptibility to fluoroquinolones in Japan. Genitourin Med 1994;70:90-3.

9 Tanaka M, Matsumoto T, Kobayashi I, Uchino U, Kumazawa J. Emergence of in vitro resistance to fluoroquinomazawa J. Emergence of in vitro resistance to fluoroquinolones in Neisseria gonorrhoeae isolated

10 Belland RJ, Morrison SG, Ison C, Huang WM. Neisseria gonorrhoeae acquires mutations in analogous regions of gyrA and parC in fluoroquinolone resistant isolates. Mo Microbiol 1994;14:371-80.

11 Tanaka M, Otsuki M, Nishino T, et al. Mutation in DNA gyrA of norfloxacin-resistant clinical isolates of Neisseria gonorrhoeae. Genitourin Med 1996;72:295-7.

12 Tanaka M, Fukuda H, Hirai K, et al. Reduced uptake and accumulation of norfloxacin in resistant strains of Neisseria gonorrhoeae isolated in Japan. Genitourin Med 1994;70: 253-5.

13 Cohen SP, McMurry LM, Hooper DC, Wolfson JS, Levy SB. Cross-resistance to fluoroquinolones in multipleantibiotic-resistant (Mar) Escherichia coli selected by tetracycline or chloramphenicol: decreased drug accumulation associated with membrane change in addition to OmpF reduction. Antimicrob Agents Chemother 1989;33 $1318-25$

14 Hirai K, Aoyama H, Irikura T, Iyobe S, Mitsuhasi S. Difference in susceptibility to quinolones outer membrane mutants of Salmonella typhimurium and Escherichia coli. Antimicrob Agents Chemother 1986;29:535-8.

15 Hooper DC, Wolfson JS, Bozza MA, Ng EY. Genetics and regulation of outer membrane protein by quinolone resistance loci $\mathrm{nfxB}, \mathrm{nfxC}$, and cfxB. Antimicrob Agents Chemother 1992;36:1151-4.

16 Kaatz GW, Seo SM, Ruble CA. Effux-mediated fluoroquinolone resistance in Staphylococcus aureus. Antimicrob Agents Chemother 1993;37:1086-94

17 Cohen SP, Hooper DC, Wolfson JS, et al. Endogenous active efflux of norfloxacin in susceptible Escherichia coli. Antimicrob Agents Chemother 1988;32:1187-91.

18 Toshida H, Nakamura M, Bogaki $M$, et al. Mechanism of action of quinolones against Escherichia coli DNA Gyrase. Antimicrob Agents Chemother 1993;37:839-45.

19 Messing J. New M13 vectors for cloning. Methods Enzymol 1983;101:20-78.

20 Sawai T, Hiruma R, Kawana N, et al. Outer membrane permeation of $\beta$-lactam antibiotics in Escherichia coli, Proteus mirabilis, and Enterobacter cloacae. Antimicrob Agent Chemother 1982;22:585-92.

21 Hirai K, Aoyama H, Suzue S, et al. Isolation and characterization of norfloxacin-resistant mutants of Escherichia coli K-12. Antimicrob Agents Chemother 1986;30: 248-53.

22 Heisig P, Tschorny R. Characterization of fluoroquinoloneresistance of Escherichia coli selected in vitro. Antimicrob Agents Chemother 1994;38:1284-91. 